\title{
Realistic Predicament and Countermeasure of the Construction of High Quality Curriculum Resource Sharing Platform in Universities
}

\author{
Jing $\mathrm{Xiao}^{1, \text { a }}$ \\ ${ }^{1}$ Academic Affairs Office, Wuhan University of Technology, Wuhan City, Hubei Province, 430070, \\ China \\ aemail:
}

Keywords: Colleges and universities; Quality curriculum resources; Sharing platform; Build; Predicament

\begin{abstract}
With the continuous development of scientific and technological information, more and more institutions of higher learning have entered a new era of information education and each school has its own high-quality curriculum resources. However, the resources owned by many universities have not been maximized. In this era of information sharing, we should strengthen the exchange of information with other universities and exchange of information resources between colleges and universities. Based on the author's learning and practical experience, this paper first analyzed the problems existing in the construction of high quality curriculum resource sharing platform in universities, and then put forward the targeted solutions.
\end{abstract}

\section{Introduction}

The continuous enrollment expansion of colleges and universities will transform elite education into mass education, which is more conducive to improving the overall quality of the people. However, behind the enrollment expansion, a series of problems, such as shortage of resources, quality of teaching and quality of students, have been gradually highlighted; colleges and universities are faced with major challenges. Solving the problem like how to make full use of the limited resources and making full use of it, can ensure the smooth development of education and teaching and ensure the quality of teaching in colleges and universities. In order to overcome the shortage of high-quality resources and the impact on the reform and development of colleges and universities, we must build a batch of high-quality courses, high-quality resources, and fully realize the sharing of high-quality resources. It can be taken as an important task to solve the shortage of resources in colleges and universities so that to ensure the continuous improvement of teaching quality. The construction of high quality curriculum resource sharing platform not only needs to realize the high quality curriculum resources, but also plays an important role in improving the teaching quality.

\section{The Problems Existing in the Construction of High Quality Curriculum Resource Sharing Platform}

There is not enough sense of sharing among the university heads. We usually say action comes with ideas. Although we have ideas, we do not necessarily have actions. But without thought, we will not act. To some extent, we can say that thought restricts our normal behavior. As the head of the university, if they do not know enough about the sharing of information resources, this action 
will not happen. Therefore, their understanding and importance of this issue is very important and critical. Many schools are now reluctant to let other schools go beyond their own with strong competitive consciousness. But I think when we compete, we can also be a cooperative relationship. We compete in cooperation and cooperate in competition so that both sides can keep on active and enterprising and have certain improvement in the academic research level. Therefore, the leaders of our universities should not only have a sense of competition, but also have a sense of sharing in order to promote the development of school. In addition, it is possible to find a very good partner so that two schools can make common development.

Lack of necessary environment and conditions for sharing resources. The library is the richest place of knowledge in every university, and is a paradise for students to study and acquire knowledge. However, the libraries in universities are basically closed and open only to students of their own. This leads to the fact that resources can not be fully utilized, and a certain knowledge acquired by students may be one-sided because of the lack of knowledge. Therefore, it can be seen that there is not much cooperation between the libraries of colleges and universities, which is almost impossible. In addition to the library, there are many laboratories, employment guidance centers, talent training centers and so on. There are no open policies in these teaching facilities at the university. In addition to the sharing of consciousness among college heads, there must be a certain guarantee for the environment and basic conditions.

The system of teaching resources sharing is incomplete, and the policy is not enough. In the management system of university in our country, the division of educational resource is compartmentalized, and the phenomenon of department is still common. Most of the educational resources in China are owned by the state and the ownership belongs to the state. However, the state is a virtual right subject, and the right to use the educational resources belongs to the school or some individuals. In some schools, colleges and universities regard the occupied resources as their own; it is better to do so without sharing it with others, and to use professional assessment in the management of higher education. Although evaluation can promote the development of discipline from the perspective of professional construction, many of the evaluation system emphasize too much on school running hardware conditions and hardware index. The direction of this macro management means undoubtedly impact on the sharing of resources, and the tendency of "small and complete" school running mode in planned economy will undoubtedly lead to a certain degree of waste of resources.

Network curriculum resources are basically closed. In college, each school has its own network of elective courses, which are basically the same. The online course resource we are going to say is a video of each school's recorded by school teachers. These videos recording teachers must be the most famous teachers in every university, and the teaching of the course must be very good, so these resources are very valuable. We can not only let the students in the class follow the video review and make further study, but also help other students outside the school to learn what they want to learn. However, the existing problem is that the opening degree of the network course resources in many universities in China is very low, and a large number of institutions are basically not open to the public.

The lack of a unified information technology system. Although the information technology in China has developed rapidly in recent years, the considerations about the platform for the exchange of curriculum resources offered by college students are largely absent on account of the sharing of information resources in many colleges and universities and usually stay in the class of teachers. Therefore, this leads to the fact that there is no unified place for colleges and universities to upload some good courses and materials for study. Each university's information technology 
system is also not normative.

\section{The Optimization Program of the Construction of High Quality Curriculum Resource Sharing Platform}

It is necessary to establish a shared information technology system. The sharing of information curriculum resources between colleges and universities must have a powerful information technology sharing system. In today's developed network environment, we can easily realize the sharing of network information resources between schools. In the Internet era, the sharing of network information between colleges and universities has changed from quantitative change to qualitative change. We can share information resources in colleges and universities over time and space. At the same time, due to the old campus network system in many schools, it is no longer suitable for the needs and demands of the present era. Some schools can choose to change the school's campus network system. At present, schools that do not have this condition can first formulate plans in this regard, and should have a clear understanding of how to transform the old campus network system. The sharing and sharing of the curriculum resources and the operability of the information technology system are of great significance for the implementation of the network remote course resource sharing in various universities.

The education department shall formulate regulations for the exchange of curriculum resources. When we have a shared information technology system that can be operated simply, we must have the relevant regulations formulated by the relevant departments as a strong guarantee for the free exchange of university information curriculum resources. If there is such a strong guarantee, our colleges and universities can expand the scope of sharing information technology education resources. Therefore, our education authorities need to establish a technical specification about the construction of distance curriculum resources as soon as possible so that the design and development of the operating system for our shared information technology system has the uniform and compliant standard. At the same time, all colleges and universities should respond positively to this policy after the establishment and implementation of this standard. Only in this way can the technology meet the requirements and design an information sharing system to jointly develop and build an educational platform for the quality of the network resources that can be shared among the vast numbers of young students.

The need for policy support. The established university information technology curriculum, educational resources sharing platform and the resources above need someone to supervise. Colleges and universities must ensure the quality of the resources uploaded to this platform, as well as the size of the shared range. At the same time, we need to invest a certain amount of money into this information platform, and support the development of information platform and the construction of infrastructure.

The government needs to invest a certain amount of money. Most colleges and universities in our country are public schools, which are built and developed by the Chinese government. Therefore, the construction of this information platform must be supported by government funds. But because our universities have different popularity and scale of schooling, the government has different investment in different schools. There must be a big gap between the funding of information technology platforms built by regular universities and key colleges and universities. As a result, each school, in addition to the government's financial aid, can seek sources of funding elsewhere, such as alumni who have graduated, companies that have worked together, and so on.

Mobilize the initiative of colleges and universities, and expand the fields of soft and hardware resources cooperation between schools. Taking the teaching community as an example, 
we should not only adopt a single form of inter school public elective courses, but also gradually expand to more fields. In the aspect of teachers, we can hire teachers or adopt mutual hiring; in terms of hardware, site mutual rent and facilities sharing can be considered; we need to share teaching and research facilities and teaching public service systems; further, we should share laboratory, sports facilities and teaching equipment, books and materials as well as the network resources; in terms of information, we can consider exchanging information and sharing information, such as sharing academic lectures; in the field of curriculum, we can take courses in each other and choose courses from each other and recognize and exchange to each other; we also can mutually open second major. In terms of cultural activities, we can consider joint development, joint hosting, roving exchanges and so on.

\section{Summary}

The sharing of quality curriculum resources will certainly promote the development and renewal of the new generation of educational teaching concepts. Therefore, it is necessary for us to build a batch of high-quality curriculum resources sharing platform with strong influence and strong competitiveness. The construction of excellent resource sharing course in colleges and universities needs to consolidate its own teaching characteristics and should learn from the others so that to avoid ignoring own cultural traditions. Institutions of higher learning should build systematic, comprehensive and overall excellent resource sharing courses in their fields of expertise, and thus train new highly skilled and applied talents.

\section{Acknowledgement}

Key project of Hubei education science plan in 2015: Innovation of co construction and sharing mechanism of high quality curriculum resources in Universities.

\section{References}

[1] Liu Ying, Luoyuan. Countermeasures and Suggestions for Opening Up and Sharing High Quality Curriculum Resources in Higher Vocational Colleges[J]. Read and Write (Journal of Education), 2016 (03): 55-56+4.

[2] Li Feng. Present Situation, Problems and Countermeasures of Curriculum Construction of Resource Sharing[J]. Computer Education, 2014, (18): 86-89.

[3] Zhang Jun, Li Haixiang, Wei Caichun, Yu Shaohong. Thoughts and Suggestions on Sharing High-Quality Curriculum Resources Among Local Colleges and Universities[J]. Guide (Mid Journal), and 2014 (07): 8-9.

[4]Hu Qing, Zhang Demin. Exploration and Reflection on the Construction of Resource Sharing in Top-Quality Courses[J]. Journal of Chongqing University of Posts and Telecommunications (Social Sciences Edition), 2013, (06): 151-153.

[5] Wang Zhongrun, LI En, Zhao Dongnuan. Current Situation, Problems and Countermeasures of Resource Sharing in Top-Quality Courses[J]. Higher Education Forum, 2010, (02): 20-23.

[6] Zhou Mingsheng, Jiang Ping. Construction of High Quality Curriculum Resource Sharing Platform in Colleges and Universities: Difficulties and Countermeasures[J]. Chinese University Education, 2008, (11): 76-78.

[7] Shi Xiaoqiu, Xue Wei. Problems and Countermeasures in the Construction of Excellent Course Sharing Resources[J]. Chinese Higher Education Research, 2005, (01): 91-92. 